\title{
Studying the therapeutic effects of hemoperfusion with continuous venovenous hemofiltration in paraquat-poisoned patients by the ratio of residual normal lung in 3D-CT image
}

\author{
Liu Peng ${ }^{1 \dagger}$, Zhang Hong-tao ${ }^{2 \dagger}$, Liang Yu-guang ${ }^{3}$, He Jin ${ }^{1}$, Li Yue-qi ${ }^{1}$, Li Gong-jie ${ }^{2^{*}}$, Zhou Yue-su ${ }^{1 *}$ \\ From 2012 PLA Emergency Medicine Annual Congress \\ Beijing, China. 9-12 November 2012
}

\section{Objective}

Paraquat poisoning(PQ) by ingestion is often fatal and is a significant public health problem worldwide.The lung is the major target organ for PQ poisoning. The study is aimed to investigate the ratio of residual normal lung in 3D-CT image in evaluating the therapic effects of continuous venovenous hemofiltration $(\mathrm{CVVH})$.

\section{Methods}

Nighty-five patients with acute paraquat poisoning were randomly divided into hemoperfusion(HP) group (46 cases) and HP-CVVH group (49 cases). The mortality, survival duration and the ratio of residual normal lung in $3 \mathrm{D}-\mathrm{CT}$ image between the two groups were compared and analyzed.

\section{Results}

There were no significant differences in mortality $(28.26 \%$ versus $24.49 \%$ ) between the two groups on day 28 after poisoning. The mean time between poisoning and death in HP-CVVH group was $(5.2 \pm 2.1)$ days, which was significantly longer than that $(3.8 \pm 1.7)$ days in HP group $(\mathrm{P}<0.05)$. The ratio of residual normal lung in 3D-CT image on 6th day after poisoning in HP-CVVH group was $(31.80 \pm 12.71) \%$,which was significantly higher than that $(25.60 \pm 14.06) \%$ in HP group $(\mathrm{P}<0.05)$.

\footnotetext{
* Correspondence: ligj307@163.com; iamldb@hotmail.com † Contributed equally

'Department of Emergency, 302 Hospital of PLA, Beijing 100039, China ${ }^{2}$ Department of Radiology, Affiliated hospital of Academy of Military Medical Sciences, Beijing 100071, China

Full list of author information is available at the end of the article
}

\section{Conclusion}

The combined therapy of HP and CVVH could prevent advances in lung injury induced by acute paraquat poisoning and prolong survival time, but failed to reduce mortality of paraquat-poisoned patients.

\section{Author details}

'Department of Emergency, 302 Hospital of PLA, Beijing 100039, China. ${ }^{2}$ Department of Radiology, Affiliated hospital of Academy of Military Medical Sciences, Beijing 100071, China. ${ }^{3}$ Department of Pharmacology, Academy of Military Medical Sciences, Beijing 100071, China.

Published: 18 December 2012

doi:10.1186/1471-227X-12-S1-A1

Cite this article as: Peng et al: Studying the therapeutic effects of hemoperfusion with continuous venovenous hemofiltration in paraquat-poisoned patients by the ratio of residual normal lung in 3D-CT image. BMC Emergency Medicine 2012 12(Suppl 1):A1.

Submit your next manuscript to BioMed Central and take full advantage of:

- Convenient online submission

- Thorough peer review

- No space constraints or color figure charges

- Immediate publication on acceptance

- Inclusion in PubMed, CAS, Scopus and Google Scholar

- Research which is freely available for redistribution

Submit your manuscript at www.biomedcentral.com/submit
() Biomed Central 